\title{
THE EFFECT OF SECANG EXTRACT (CAESALPINIA SAPPAN LINN) ON THE WEIGHT AND HISTOLOGY APPEARANCE OF WHITE MALE RATS' HEARTS INDUCED BY ISOPROTERENOL
}

\author{
KRISTIANA NUGRAHENI, FADLINA CHANY SAPUTRI* \\ Department of Pharmacology, Faculty of Pharmacy, Universitas Indonesia, Kampus UI Depok, Indonesia. \\ Email: fadlina.chany@farmasi.ui.ac.id
}

Received: 21 April 2017, Revised and Accepted: 18 August 2017

\section{ABSTRACT}

Objective: This study was conducted to determine the cardioprotective effect of secang extract on the heart cells of rats who suffered from myocardial infarction induced by isoproterenol.

Materials and Methods: Sprague Dawley rats were divided into six groups: Normal control, negative control, control extract ( $200 \mathrm{mg} / \mathrm{kg}$ ), and three different dose extract groups (50,100, and $200 \mathrm{mg} / \mathrm{kg}$ body weight) that were given treatment for 30 days, and then, induced with isoproterenol. Observations were made for changes in the macroscopic appearance, cardiac weight, and histology of the cardiac organ.

Results: The results showed a decrease in the incidence of myocardial infarction in rats given secang extract. The infarction area decreased with increasing doses of extract. The weight of the heart in the control extract group was smaller than in the negative control group.

Conclusions: Damage to heart cells, seen in the microscope, decreased with increasing doses.

Keywords: Caesalpinia sappan Linn, Secang extracts, Myocardial infarction, Isoproterenol, Cardioprotective.

(c) 2017 The Authors. Published by Innovare Academic Sciences PvtLtd.This is an open access article under the CC BY license (http://creativecommons. org/licenses/by/4. 0/) DOI: http://dx.doi.org/10.22159/ijap.2017.v9s1.35_41

\section{INTRODUCTION}

Myocardial infarction is a common type of ischemic heart disease. Myocardial infarction occurs when the myocardium cells undergo ischemia that exceeds the critical threshold, resulting in irreversible cell damage. Although clinical care has enhanced, public awareness of health has increased, and health innovations are widely used, myocardial infarction remains the leading cause of death worldwide [1]. Myocardial infarction is the primary lethal result of prolonged myocardial ischemia. Myocardial cells begin to decease approximately 20 minutes after a loss of oxygen supply. After this period, cells are unable to produce ATP aerobically and fail to meet energy requirements [2]. A lack of oxygen supply in the myocardium cells is due to a coronary artery blockage caused by atherosclerosis. Atherosclerosis is the hardening of arteries caused by the accumulation of fat deposits, platelets, neutrophils, monocytes, and macrophages throughout the intima tunica region (endothelial cell layers). Risk factors that affect atherosclerosis include hyperlipidemia and inflammation, both of which play a vital role in the progression of atherosclerotic plaques [3]. Inadequate oxygen flow in myocardial cells results in necrosis of the myocardium. The occurrence of necrosis in the myocardium is related to the formation of free radicals that trigger the release of cytokines. The cytokines that affect myocardium cell injury are tumor necrosis factor alpha (TNF- $\alpha)$, interleukin-6 (IL-6), IL-1, and IL-8 [4].

Indonesia is a nation that is rich in medicinal plants. One of the plants that has medicinal properties is the secang plant (Caesalpinia sappan Linn). C. sappan Linn is known as a natural dye product that produces a red. Secang is also used as an herbal remedy for inflammation and increased blood vessel flow. Based on previous tests in vitro, it is known that the brazilin content of secang is a compound that can provide anti-inflammatory effects [5]. In addition, secang shows antiinflammatory effects by decreasing the infract area of a brain that suffers from ischemic stroke [6]. With its anti-inflammatory activity and antioxidant properties, secang is predicted to be able to inhibit the death of myocardial cells by protecting them against oxidative stress and inhibiting the secretion of proinflammatory cytokines which can cause damage. In this study, experiments were conducted to determine the effect of secang extract on the heart cells of rats induced by isoproterenol. The macroscopic appearance, cardiac weight, and histology of the cardiac organ were carried out for the observation. This study was done to test the cardioprotective effect of secang wood extract on the incidence of myocardial infarction through antiinflammatory mechanisms.

\section{MATERIALS AND METHODS}

Materials

This study had been approved by the Ethics Committee, Faculty of Medicine Universitas Indonesia (Letter Number: 401/H2.F1/ ETIK/2014). A material used for this research was secang extract obtained from Javaplant, Surakarta, Indonesia. The chemicals used were isoproterenol (SIGMA Chemical, Darmstadt, Germany), 0.9\% sodium chloride ( $\mathrm{NaCl}$ ) solution (Sigma-Aldrich, Nucleos, Singapore), Bouin solution (Sigma-Aldrich, Nucleos, Singapore), 70\% alcohol solution (Jayamas Medica Industri, Sidoarjo, Indonesia), and 10\% formalin solution (Sigma-Aldrich, Nucleos, Singapore).

\section{Methods}

\section{Induction of myocardial infarctions}

The animals used in this study were white, male Sprague Dawley rats weighing between 200 and $250 \mathrm{~g}$. Animals were divided into six groups: Normal control, negative control (ISO), control extract, and three different doses of secang extract groups. Based on Ansari, Bhandari, and Pillai's [7] studies on rats, isoproterenol was administered at a dosage of $85 \mathrm{mg} / \mathrm{kg}$ body weight per $24 \mathrm{hrs}$ for 2 days to induce myocardial infarction. Previously, animals were given a pretreatment of secang extract with three variations of doses $(50,100$, and $200 \mathrm{mg} / \mathrm{kg}$ body weight) for 30 days. A 24 hrs after the last induced infarction, the animal was dissected for its heart organ. 
Macroscopic observations and experimental animal heart weight After the experimental animals were dissected for their heart organs, the wet weight of the heart organs was measured. Heart organs taken from experimental animals were cleaned with $0.9 \%$ sodium chloride solution then drained. After cleansing and draining, photographs of each heart organ were taken and the macroscopic appearance of each group compared. After that, the heart organs were weighed using an analytic scale. Furthermore, statistical analysis of the weight data of the experimental animals was done.

\section{Observation of histology preparations of the heart}

After weighing the experimental animal hearts, the heart organs were submitted for histology preparations. The apical part of the heart organ was cut to make the histology preparation. Several observations of the histology preparations were made. The observed conditions were the necrosis of the nucleus of heart muscle cells, along with the entire cell; the presence or absence of neutrophil infiltration in cardiac muscle tissue; and the occurrence of edema in cardiac muscle tissue. These observations were recorded, in terms of the amount of cardiac muscle tissue damage, using the scoring system below (Table 1 ).

\section{RESULTS AND DISCUSSION}

\section{Heart weight change in rats}

After the rats were sacrificed for their hearts, six hearts in each group were weighed. As shown in Fig. 1, the mean cardiac weight between the normal group and the negative group induced by isoproterenol showed a significant difference $(p<0.05)$, where the weight of the heart induced by isoproterenol was greater than that of the normal heart. The increase in heart weight, associated with increased water content and intramuscular space edema, agreed with results in previous studies that observed the swelling of the intramuscular space and cellular infiltration after induction of myocardial infarction [1]. The heart weight of rats that were given a pretreatment with secang showed a decrease in heart weight compared to the negative group, although the weight difference was not significant $(p>0.05)$. The amount of weight loss of the heart was observed to be dose-dependent. From the data obtained, it appears that secang extract can protect rat heart muscle from myocardial infarction induced by isoproterenol.

\section{Macroscopic observation of rat heart}

After the weighing process, macroscopic observations were done to determine the presence or absence of infarction in the heart of each test group. The results of the observations can be seen in Figs. 2 and 3. In Fig. $2 \mathrm{~b}$, it can be seen that the apex of the heart is white, showing an incidence of infarction in that area. Fig. 2c, which is the heart of the group given a dose of $200 \mathrm{mg} / \mathrm{kg}$ of extract per body weight without induction of isoproterenol, had the same macroscopic appearance. Fig. 2a shows a normal control. Based on these results it can be stated that secang extract has no effect on morphological changes in the normal heart.

Table 1: Scoring system of heart muscle tissue damage

\begin{tabular}{lll}
\hline Parameter & Score & Category \\
\hline Myocardial necrosis & - & Nil \\
& + & Mild \\
Inflammatory cell infiltration & ++ & Moderate \\
& +++ & Severe \\
Interstitial edema & - & Nil \\
& + & Mild \\
& ++ & Moderate \\
& +++ & Severe \\
& - & Nil \\
& + & Mild \\
\hline Scoring & ++ & Moderate \\
& +++ & Severe \\
\hline
\end{tabular}

Scoring system adapted from Li, Wang, Guo, Deng, Zheng, Xu, Wu, and Dai, 2012
From data observation, it can be suggested that pretherapy, using secang extract, can reduce the risk of myocardial infarction. This can be seen in Fig. 3, where there is a decline in the cardiac infarction heart area in groups that are given secang extract at a dose of $50 \mathrm{mg} / \mathrm{kg}$ body weight (a), $100 \mathrm{mg} / \mathrm{kg}$ body weight (b), and $200 \mathrm{mg} / \mathrm{kg}$ body weight (c). The higher the dose given the fewer is the infarcts. At a dose of $200 \mathrm{mg} /$ kg body weight, the macroscopic appearance almost resembles a normal heart. However, the magnitude of the infarcts between doses cannot be measured quantitatively, so the data obtained cannot be used to determine the severity of the infarction.

\section{Microscopic observation}

Once the hearts were observed macroscopically, histological samples were made to observe infarction changes microscopically. The results are illustrated in Figs. 4 and 5. Figs. 4 and 5 show the histologic pictures of each group. Normal groups do not show any myocardial necrosis, leukocyte infiltration, or interstitial edema. The control extract group also shows the same results, proving that secang extract does not

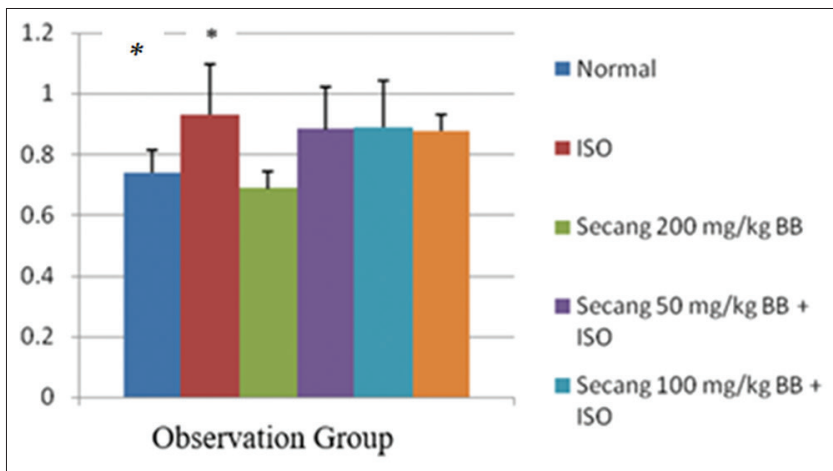

Fig. 1: The rat weight ratio comparison chart. ${ }^{*} \mathrm{p}<0.05$, the norma group had a significant difference when compared with the negative control group (ISO)

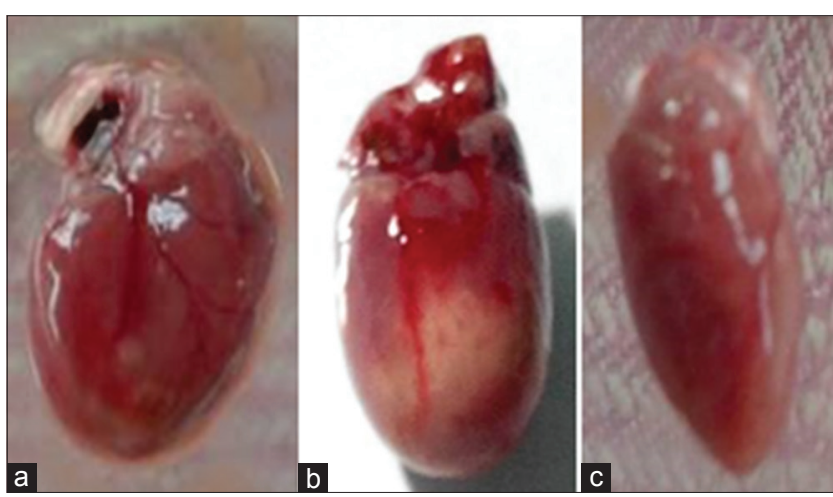

Fig. 2: Macroscopic heart observations: (a) Normal heart (b) negative control heart; (c) extract control heart

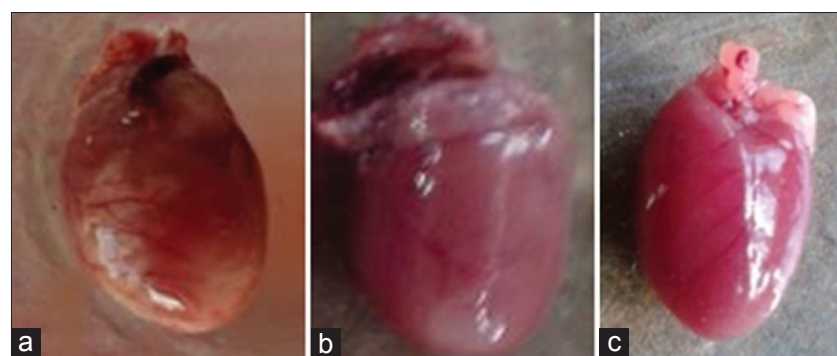

Fig. 3: Macroscopic heart observations: (a) Dose 1 (Secang $50 \mathrm{mg} / \mathrm{kg}$ body weight + ISO); (b) Dose 2 (Secang $100 \mathrm{mg} / \mathrm{kg}$ body weight + ISO); (c) Dose 3 (Secang $200 \mathrm{mg} / \mathrm{kg}$ body weight + ISO) 


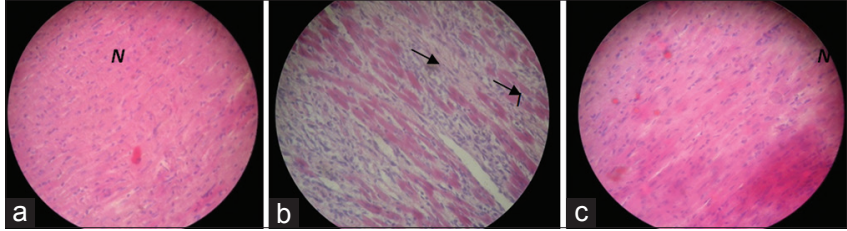

Fig. 4: Histology of the normal heart, the negative control, and extract control with 400 times magnification, (a) normal, (B) negative control, (C) extract control
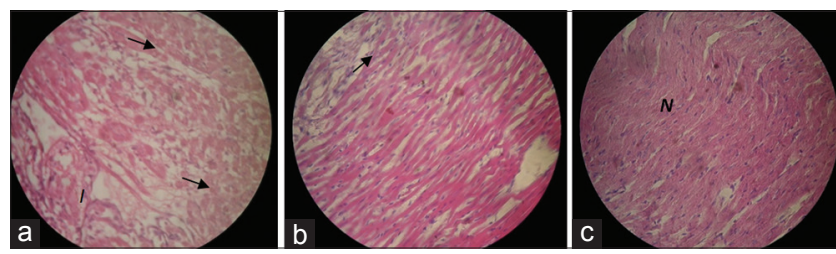

Fig. 5: Cardiac histology pretreatment with secang extract (Caesalpinia sappan Linn). (a) Dose 1, (b) dose 2, and (c) dose 3 with 400 times magnification

Table 2: The effect secang extract has on histological changes in experimental rat hearts

\begin{tabular}{|c|c|c|c|c|c|c|c|c|c|c|c|c|c|}
\hline \multirow[t]{2}{*}{ Group } & \multirow[t]{2}{*}{$\mathbf{n}$} & \multicolumn{4}{|c|}{$\begin{array}{l}\text { Myocardial } \\
\text { necrosis }\end{array}$} & \multicolumn{4}{|c|}{$\begin{array}{l}\text { Inflammatory cell } \\
\text { infiltration }\end{array}$} & \multicolumn{4}{|c|}{$\begin{array}{l}\text { Interstitial } \\
\text { edema }\end{array}$} \\
\hline & & - & + & ++ & +++ & - & + & ++ & +++ & - & + & ++ & +++ \\
\hline Control & 5 & 5 & 0 & 0 & 0 & 5 & 0 & 0 & 0 & 6 & 0 & 0 & 0 \\
\hline ISO & 5 & 0 & 0 & 0 & 5 & 0 & 0 & 5 & 0 & 3 & 0 & 0 & 2 \\
\hline Extract & 5 & 6 & 0 & 0 & 0 & 5 & 0 & 0 & 0 & 6 & 0 & 0 & 0 \\
\hline Dose 1 & 5 & 0 & 0 & 1 & 4 & 0 & 0 & 1 & 4 & 0 & 2 & 3 & 0 \\
\hline Dose 2 & 5 & 0 & 1 & 4 & 0 & 0 & 1 & 4 & 0 & 1 & 4 & 0 & 0 \\
\hline Dose 3 & 5 & 0 & 5 & 0 & 0 & 0 & 5 & 0 & 0 & 3 & 2 & 0 & 0 \\
\hline
\end{tabular}

-: No abnormality, +: Mild, ++: Moderate, +++: Severe

have a negative effect on heart muscle cells. In contrast, the negative control group shows severe myocardial necrosis, moderate leukocyte infiltration, and interstitial edema in some heart muscle tissue.

In Fig. 5, pictures show that the dose 1 group has an infiltration of neutrophils which disappears with dose 2 and dose 3 . The infiltration of neutrophils at dose 1 in Fig. 5 is less compared to negative control in Fig. 4. Table 2 shows a significant decrease in severity $(p<0.05)$ between dose 1 , dose 2 , and dose 3 . This shows that the secang extract can decrease the incidence of infarction.

Based on previous studies, inflammatory agents known are TNF- $\alpha$, IL-1 $\beta$, and IL-6. Pro-inflammatory cytokine necrosis factor- $\alpha$ produces cardiotoxic effects, suppresses contractile function, reduces $\beta$-adrenergic inotropic response, and activates pro-apoptotic pathways in the myocardium. $\alpha$-factor tumorecrosis is secreted in large quantities in the myocardium causing ischemia and reperfusion, factors that are thought to have a significant effect on cell apoptosis. Therapeutic agents with components that can resist apoptosis inhibit cell death and prevent injury $[8,9]$.

As has been reported in previous studies, IL-1 $\beta$ expression, IL-6, and TNF- $\alpha$ are responsible for the activation of inflammatory cascades and the continued disturbance of myocardial damage $[8,9]$. The $\alpha$-factor is secreted in copious quantities in isoproterenol-induced myocardium [10]. Pre-treatment with secang extract (Caesalpinia sappan Linn) decreases expression of pro-inflammatory cytokine gene in isoproterenol-induced myocardium, thereby reducing the expression of proinflammatory cytokines, inhibiting inflammation and preventing myocardial injury induced by isoproterenol

\section{CONCLUSION}

Based on the results of the study, to determine the cardioprotective effect of secang extract, it can be concluded that administering a pretreatment of secang extract in isopropanol induced-male white rats can protect heart muscle cells. This was seen through the decrease in heart weight and improvement in the histology of the heart.

\section{REFERENCES}

1. Patel V, Upaganlawar A, Zalawadia R, Balaraman R. Cardioprotective effect of melatonin against isoproterenol induced myocardial infraction in rat: A biochemical, electrocardiographic and histoarthitectural evaluation. Eur J Pharm 2010;644(1-3):160-8.

2. Corwin E. Handbook of Pathophysiology. $3^{\text {rd }}$ ed. Philadelphia, PA: Lippincott William and Wilkins; 2008.

3. Loscalzo J. Molecular Mechanisms of Atherosclerosis. United Kingdom: Taylor and Francis; 2005.

4. Pantos C, Mourouzis I, Cokkinos D. Myocardial Ischemia: From Mechanisms to Therapeutic Potentials. United States of America: Springer; 2006.

5. Washiyama M, Sasaki Y, Hosokawa T, Naguno S. Anti-inflammatory constituens of sappan lignum. Biol Pharm Bull 2009;32(5):941-4.

6. Shen J, Zhang H, Lin H, Su H, Xing D, Du L. Brazilein protects the brain against focal cerebral ischemia reperfusion injuri correlating to inflammatory response suppression. Eur J Pharmacol 2007;558(1-3):88-95.

7. Ansari MN, Bhandari U, Pillai KK. Ethanolic Zingiber officinale R. Extract pretreatment alleviates isoproterenol-induced oxidative myocardial necrosis in rat. Indian J Exp Biol 2006;44(11):892-7.

8. Prince P, Rajakumar S, Dhanasekar K. Protective effects of vanillic acid on electrocardiogram, lipid peroxidation, antioxidants, proinflammatory markers and histopathology in isoproterenol induced cardiotoxic rats. Eur J Pharm 2011;668(1-2):233-40.

9. Kumaran KS, Prince PS. Protective effect of caffeic acid on cardiac markers and lipid peroxide metabolism in cardiotoxic rats: An in vivo and in vitro study. Metabolism 2010;59(8):1172-80.

10. Benjamin IJ, Jalil JE, Tan LB, Cho K, Weber KT, Clark WA. Isoproterenol-induced myocardial fibrosis in relation to myocyte necrosis. Circ Res 1989;65(3):657-70. 